Portland State University

PDXScholar

1973

\title{
Identifying and Defining Natural Service Delivery Systems
}

James R. Garrison

Portland State University

William J. Teverbaugh

Portland State University

Follow this and additional works at: https://pdxscholar.library.pdx.edu/open_access_etds

Part of the Social Work Commons

Let us know how access to this document benefits you.

\section{Recommended Citation}

Garrison, James R. and Teverbaugh, William J., "Identifying and Defining Natural Service Delivery Systems" (1973). Dissertations and Theses. Paper 1605.

https://doi.org/10.15760/etd.1604

This Thesis is brought to you for free and open access. It has been accepted for inclusion in Dissertations and Theses by an authorized administrator of PDXScholar. Please contact us if we can make this document more accessible: pdxscholar@pdx.edu. 
IDENTIFYING AND DEFINING

NATURAL SERVICE DELIVERY SYSTEMS

\author{
by \\ James R. Garrison William J. Teverbaugh
}

A research report submitted in partial fulfiliment

of the requirements for the degree of

MASTER OF SOCIAL WORK

Portland State University

1973 


\section{IDENTIFYING AND DEFINING}

\section{NATURAL SERVICE DELIVERY SYSTEMS}

\section{by}

James R. Garrison

William J. Teverbaugh

Approved :

Diahe Pancoast, M.S.W., Chairman

Shirley Kennedy, Ph. D.
Date:
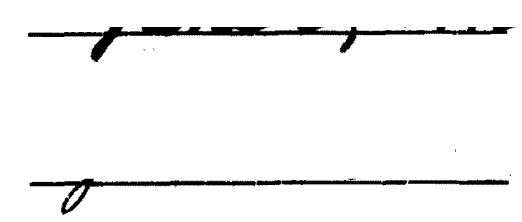
TABLE OF CONTENTS

Page

LIST OF TABLES •

INTRODUCTION . . . . . . . . . . . . . . 1

Background of Interest. . . . . . . . . . 1

Natural Systems Defined . . . . . . . . . 3

RESEARCH OF THE LITERATURE • . . . . . . . . . 4

Examples of Natural Systems . . . . . . 5

Indigenous Workers in Natural Systems. . 9

Involvement of Professionals and

Agencies in Natural Systems..... . . 14

METHOD . . . . . . . . . . . . . 15

S.E. Neighborhood. . . . . . . . . 15

Definition of Natural Systems
Categories....... . . . . . 16

Selection of Participants. . . . . . 17

Interview Procedure. . . . . . . . 18

Corbett-Terwilliger Neighborhood. . . . . 18

Area Described . . . . . . . . 18

Selection of Participants. . . . . 19

ANALYSIS OF DATA . . . . . . . . . . 20

Classification of Support Provided. . . 20

Classification of Support Received. ... 21

S.E. Neighborhood... . . . . . . 23 
Page

Corbett-Terwilliger Neighborhood. . . . 24

Combined Analysis......... . . 25

CONCLUSIONS AND DISCUSSION . . . . . . . 25

Supporting and Supported Persons. . . 25

Managers . . . . . . . . . . . . 27

User . . . . . . . . . . . . . . 27

Service Networks. . . . . . . . . 28

other Findings. . . . . . . . . . . 36

SUMMARY . . . . . . . . . . . . . 39

IMPLICATIONS . . . . . . . . . . . . 42

APPENDIX . . . . . . . . . . . . . 44

BIBLIOGRAPHY . . . . . . . . . . . . 54 


\section{LIST OF TABLES}

Table

Page

1

Interview Design . . . . . . . .

Classification of Natural system Services........... . . 46

Identification of Individuals Interviewed, St. Francis Area. .

Number of Services. Received and Provided by Supported and Supporting Persons . . . . . . .

Frequency of Help Received by Supported Persons. . . . . . . . 48

Percentage of Supported Persons Receiving Help.......... .

Help Given by Supporting Persons, st. Francis area....... . . 50

Percentage of Supporting Persons Giving Help... . . . . . . . 51

Frequency of Help Received by Supported Persons, Corbett-Terwilliger...

Help Given by Supporting Persons, Corbett-Terwilifer area.... 


\section{Introduction}

One aspect of reality that professional social workers are experiencing in the course of performing social work is what the authors will refer to as natural service delivery systems. We use this particular term for clarity, yet there are questions that still remain. Are there, in fact, measurable phenomena that we can call natural service delivery systems? If these systems exist, what kind of services do they deliver or what types of services do they imply? If these services do exist and if we recognize them, what are the implications for professional social workers? How does our knowledge base allow for us to intervene in these systems with minimal danger of destroying or changing their character and still use them as resources?

These questions arose after both authors had worked within communities where, because of the nature and composition of the populations, it was apparent that natural services were being provided by one neighbor to another or by one friend to another. It was difficult to explain those services in relation to our own roles as social workers. Often it seemed as if there was in existence a procedure that we did not understand in terms of a worker-client relationship.

It is from this history of interest and with these questions in mind that we began our research into the area of natural service delivery systems. We have attempted to identify, define 
and describe these systems in order to understand the processes by which they work. We felt that after we understood what in fact was happening in these communities, we would be better able to deal with these systems as social workers. It is our assumption that in communities there exist natural service delivery systems as we will define them.

Investigation: into the internal workings of communities is difficult. It consists of observing behavior, the phenomena that exist, recording data about it and then interpreting the accumulated data. Much of the orientation of professional social workers and social work students is agency-based in nature. This presents at least a two-fold dilemma to the social work student; that is, lack of encouragement to explore processes in the community, as well as lack of references in the social work literature to follow within the community. We will attempt to make a statement of definition of "natural system" that is to be used in this study. As of yet, the research on natural systems has been given other names by various disciplines. Sociology and psychology have led in the inquiries into this area. It is $\operatorname{logica} 1$, especially for a student of social work, to become familiar with the community in which he is involved. Yet how to function within that community and the various subsystems which are and have been used as coping devices by the community member is 
often neglected in social work education. The neglect is not that of the student, nor of the school, but rather an assumption that an existing agency knows how to work within the community and that the social work students, by some process, will absorb the knowledge from the agency. The fact is that even though most agencies attempt to understand the community, for various reasons they fall pathetically short of either understanding or functioning within the internal systems that have evolved within the community to support its members. Whatever the cause of this lack of understanding, it is obvious in such books as Street-Corner Society and Tally's Corner that these existing "street-corner societies" are intricate, self-contalned and most often more functional, especially communicatively, than an agency to which a social worker might possibly become at tached.

Defining a natural system is a difficult task. There are many variables; however, these variables are viewed as having a particular function. This function is emotional, mental and often times physical survival supplied by significant others in a familiar proximity. We have not limited our view of natural systems to any one geographical area nor to any socio-economic or racial group. It is believed that natural systems exist wherever people exist. For each person, in order to function, self-esteem needs to be felt through the development of an adequate role within a "safe" environment, be that a street 
corner, a certain block, a particular bar, or any other place where people exist. In order for this natural system to allow for coping, for self-esteem to survive, the system by necessity must be closed to all who are not of the regular population of that area. Outsiders tend to be disrupters. In order to enhance without disruption, the social worker must be knowledgeable within the area in which he is involved, but must not have a predetermined hidden agenda outlined for that system. He must come to the system to learn from the system if he is to eventually be a resource or facilitator to the system. C. West Churchman defines a system as "a set of parts coordinated to accomplish a set of goals" (Churchman, 1968, p. 3). This concept of systems is appropriate for the project described in this paper. It is unrealistic to believe that a social worker or any outsider can become a part of this system. A social worker, however, does have more mobility and access to resources outside the system than those in the natural system. A social worker can assist or be a supportive agent for this natural system.

Research of the Literature

Articles concerning natural systems and working within these systems to provide services are still infrequent in professional journals. What has been defined in the introduction as natural service delivery systems are described in a few articles and books. Natural services provided by bartenders have been reported both in professional and nonprofessional articles. In some research, stress is placed 
on the importance of a community in providing service to residents of an area. Dominant leaders also contribute to the role of providing natural services. A second phase of the reporting of natural service delivery systems is the concept of the indigenous nonprofessional. Research supporting the use of indigenous nonprofessionals describes these individuals as aiding natural systems by providing communication between socio-economic groups, furthering responsiveness to lower economic communities' needs and providing support systems for the community. A third area of study involves reports of infiltration into natural systems to provide professional or agency-based services. These articles tend most often to involve mental health services, such as crisis counseling. The existence of natural service delivery systems has been intimated in books and articles such as Elliot Liebow's Tally's Corner (1967). Liebow reveals how certain natural systems work and the types of support provided by individuals to other individuals. It painstakingly outlines the necessity for the existence of supporting persons who play out their roles in the drama of survival on the street. Although the goals of these systems are often unstated, they seem to deal mainly with survival; day-to-day maintenance and emotional support. The intricacies of low income areas are also portrayed. Two of the articles surveyed describe the use of bartenders as types of indigenous therapists. Dumont's research (1967) on the "Tavern Culture" used a participant-observer approach and discovered that bartenders do indeed develop 
effective natural service delivery systems. By infiltrating the tavern culture without hindering the natural delivery system of the bartender, inconspicious observations were made without destroying the effectiveness of existing systems. Irwin's article (1972), "They Tell It to Bartenders and Beauticians", is an example of research which is being printed in nonprofessional journals. The work by Irwin is aimed at the concept of the indigenous nonprofessional therapist. The article describes North Dakota residents who utilize beauticians and bartenders as mental health experts. For example, one beautician interviewed stated that many women may spend most of the $1 \frac{1}{2}$ hours in the stylist's chair unburdening themselves by confiding to the beauty operator. A bartender stated that he could sense when a customer begs for help. Both bartenders and beauticians indicate that providing a listening ear is what is necessary for many of their customers to maintain in their daily life situations.

Curtis and Zurcher (1971), in their research of low socioeconomic areas discovered that lower class interaction patterns were found to be maintained largely in the local, relatively intimate settings of the family and the immediate neighborhood. One of the assumptions with which we began our research was that the family and neighborhood are essential to survival in lower economic strata. This article tends to confirm our findings. Curtis and Zurcher support our belief that survival in lower class neighborhoods is contingent on the development 
of natural support systems. In these areas, there is a higher tendency to be secure in knowing neighbors, friends, and those in the neighborhood that can be trusted or relied on. It is, in fact, crucial for survival that these interactions happen. Implicit in our study is the idea of community. Community refers to an aggregate of people who occupy a common and bounded territory within which they establish and participate in common institutions. In "Community in Social Work", edited by Chatterjee, five schools of approach are discussed. Even though these articles discuss different aspects, the authors offer a convincing argument toward acceptance of the concept described as "community attitudes" (Chatterjee, 1968, p. 125). The concept exists as a dynamic component of community interaction. Awareness of a feeling of community by its members tends to enhance the workings of a natural system. Research on low socio-economic communities maintain that since lower class individuals have the opportunity to have more dependency on each other for basic survival needs, there is more feeling of community or togetherness. Our study focused on two geographically distinct communities, both are of low economic status.

The individuals who provide access to the natural service delivery systems are termed indigenous nonprofessionals and, as defined by Reiff and Riessman, have the capability of acting as a bridge between the middle class and/or professionals and the clients from lower socio-economic groups (Reiff \& Riessman, 
1965, p. 4). The bridge exists to specify and define needs. Implicit in this concept is that people drawn from lower socio-economic strata may have special skills for establishing communication across class 1 ines. Because of what the indigenous nonprofessional is, there is a tendency to do what the professional could not do and should not do. Even professionals who have excellent relationship skills are limited by the nature of their clients perceiving them as experts. Because the nonprofessional is not restricted by agency requirements, it presents a relationship that is not guided by time nor avaliability limitations and can be viewed as a key to effective program participation on the part of the poor. It is this very type of relationship that nonprofessionals can establish. "He 'belongs;' he is a 'significant other;' he is 'one of us.' He can be invited to weddings, parties, funerals, and other gatherings--and he can go." (Reiff\& Riessman, 1965, p. 7). The indigenous nonprofessional can play a more flexible role in the service relationship because there is no set definition of how he must act beyond the mores of his group. Reiff and Riessman view the indigenous worker as having utilized many skills in the community development or mental health programs. The skills are primarily natural empathy and familiarity with the community and conditions which prevail.

Reiff and Riessman (1965) indicate that it is obvious that the indigenous nonprofessional has the potential to make 
and to maintain contact with those who will not or cannot utilize the services of existing agencies. In order for there to be an effective change in the character of service delivery, outreach to the community and determination to stay involved on the part of the outreach nonprofessional staff (that is, the indigenous nonprofessional staff) is essential. Thus, the indigenous nonprofessional not only provides this involvement, but can greatly increase manpower resources. They can serve in ways that are significant and more appropriate and can effectively increase utilization and communication within the client population. They can bridge the social distance by bringing together the needy, the server, and the served. Programs operating on the "Helper Therapy" principle (Reiff and Riessman, 1965, p. 9), such as AA, Synonon, SCORE, and Recovery, are designed to help the addict, alcoholic and mentally 111 person help himself by aiding others. This concept is viewed as one way the indigenous nonprofessional provides a service in his work with community people. This helping relationship can be therapeutic not just to the people served, but also beneficial personally to the nonprofessional, thus increasing effectiveness within the nonprofessional role in helping the community.

$$
\text { C. Jeffers (1967), in her book Living poor, discusses }
$$
the indigenous helper and the low income individual. Being a participant observer led Jeffers to the realization that there 
are some large differences between the ways in which many low income people see and regard themselves, and the ways in which they are seen and regarded by outsiders. Definite implications can be seen in the importance of the indigenous workers living in proximity to the part of the community in which they work. The original definition of the indigenous leader as an individual who could bridge a language and culture gap between a foreign expert and the population of the country is not how the term is presently used in social work. This original meaning seems to imply more of a cultural gap than a community gap. A criticism that Jeffers makes of the indigenous leader is that dependence upon such persons may lead to a false assumption or assumptions about what people want, and under-estimations of their access and the actuality of their needs, wants, and what they get in promises. One of her conclusions about the poor is that their language is direct and that it graphically expresses the needs and demands of life. The importance of this is that readiness to listen and the ability to understand is what opens doors. As has been mentioned previously and again reaffirmed by Liebow (1967) and Jeffers (1967) that rather than language impediments restricting communication, feeling of loneliness and isolation make for appearance of impediments of communication. Jeffers states that the principle components of effective communication are likely to be a demonstration of interest and a sympathetic ear. What is pointed out in most of the literature cited is that this interest or sympathetic ear can be provided not only 
by a professional, but often times by someone who is aware of the situation, concerned about the totality of the community and where the individual is involved in that community. The natural system provider seems to be one of those individuals in the community that can be involved as well as being trusted. Caplan's work (1972) on support systems states that any person who is dealt with is a unique individual. The persons significant to him are those interested in him in a personalized way. They speak his language. Caplan describes three elements of significance that help the individual mobilize his psychological resources and master his emotional burdens: 1) sharing his task, 2) providing him with extra supplies of money, materials and skills, 3) and cognitive guidance to improve his handing of situations. "From the point of view of buffering the individual against the burden of defective feedback in the general community, support systems may operate in two ways: they may collect and store information about cues in the outside world and offer guidance and direction to the individual so that they help him to find safe paths to travel and systems to interpret in a balanced, reality based way. Feedback cues would otherwise be incomprehensible to him." (Caplan, 1972, p. 8). Support systems may also act as a refuge or sanctuary where the individual may return to rest, recuperate between his exploits into a stressful environment. Caplan uses a support system in implying an enduring pattern of 
periodic ties that play a significant part in psychological and physical integrity of the individual over time.

In a new publication, edited by Anderson and McClean (1971), it is noted in referring to suicide prevention that "the community is the focus in primary prevention." In this community prevention scheme, the authors refer to the term "gate-keeper" as those "formal and informal helping people, who by virtue of their occupational and/or social position in the community...can have a major effect." For example, one writer believes that "...future resources to operationalize prevention of suicide and other gross mental health problems are groups of lay volunteers." (Anderson \& McClean, 1971, p. 84). They suggest extending the concept of the indigenous worker to the indigenous lay volunteer who would be trained in problem solving and consultation skills. It seems that such helpers may be able to respond both to needs for sincere, caring human resources and for realistic help in tapping necessary organizational or bureaucratic resources that exist but appear somewhat remote or alien from the person in need.

Shapiro's work (1969) with dominant leaders among slum hotel residents reports on observations about the persons who emerged as dominant leaders in the single room occupancy population. Dominant leaders of the group provide a matrix of physical and emotional care. Shapiro was able to show that these functions of caring, protection and personal relationships are similiar to those performed by mental health workers in bridging the gap between the single poor and sick persons and the services to which he is entitled. 
Another study involving indigenous workers is reported by Philitps, Goldman and Kogan (1971). Their research with family day care by AFDC recipients determined that mothers on the AFDC program could be used effectively as providers of day care.

In Torrey's (1969) "The Case for the Indigenous Therapist", reports are made of the therapeutic effectiveness of the indigenous nonprofessional. Torrey defines the term indigenous therapist as a person who is sanctioned by a particular culture or subculture to do psychotherapy, even though he has not been so trained by acceptable western professional standards. This would include a wide range of individuals from shamen, witch doctors and medicine men to college students working in mental hospitals, housewives working as psychotherapists and neighborhood residents being used as mental health assistants in community mental health centers. There is a distinction in the definition of the indigenous therapist as described by Torrey (1969) and the natural neighbor concept we are describing in this paper. For an example of the difference, Bergman (1972) described the intricate training that the apprentice medicine man must undergo to become a tribally accepted medicine man. Thus, the broad inclusion of a wide range of indigenous psychotherapists, social workers or helpers is not what is meant here as a natural system neighbor. 
Recent articles describe attempts to provide services of professionals or agencies to lower economic areas without interferring with existing natural systems. In "Downtown Is the Office", Edwards and Schmidt (1971) describe the utilization of non-multiservice agencies and the need for smaller, more easily accessible service facilities.

In Taber's article (1971) on "systems Approach to Mental Health Services in a Black Ghetto," the researchers focus on two small natural groups; a social work network composed primarily of mothers of highly disorganized families with young children and a peer subsystem of fourteen to seventeen year old boys. They were able to utilize the indigenous system in such a way that the members of the natural groups were given mental health services without being required to perceive themselves as patients.

Marshall and Finan (1970) were able to utilize indigenous nurses as crises counselors. Potsubay described Vermont nurses handling psychological crises in rural communities.

The importance of a trust relationship in providing support that will be accepted is described in Levitt, Brown and LeWar's (1968) studies. These studies of a community mental health project determined that consultation to an urban welfare center serving a single room occupancy hotel could utilize and help, work with or train indigenous resident leadership individuals. 
other studies involving the use of agencies and professional workers in natural systems have been made by Maas (1971). Mass set up four proposals for the betterment of environments for children with parents on welfare. Part of these proposals consisted of the utilization of natural services in poverty neighborhoods.

Collins and Watson (1969) studied natural neighbors and natural systems of service delivery in family day care. Collins and Watson determined that a social worker would be best utilized as a consultant to the already existing natural day care mothers. These studies show that there are various ways in which people in specific situations provide and receive support on an informal basis. The review of the literature generally indicates that there are various possibilities for informal service provision and receipt. The nature of our research differed in focus from the other research reviewed. On the basis of this difference, we developed definitions which were essential for our purposes.

Method

our approach to studying specific natural systems of service delivery began with the selection of two distinct communities in the city of Portland: 1) the southeast community served by the St. Francis parish, and 2) the Corbett-Terwilliger neighborhood. The study was designed to investigate, identify and define individuals in these neighborhoods who seem to be able to provide 
help in some way to their neighbors and to other members of the community. Due to the exploratory nature of this study, the intent was to interview and to outline certain basic patterns of types of help, the nature of help given or received, to develop a working vocabulary to be able to communicate the information found and to develop a working manual for further and more in-depth investigation.

\section{S.E. Neighborhood}

The southeast community served by the St. Francis parish is bordered by S.E. 12 th and Burnside and by S.E. Division and S.E. 39 th. It is considered to be a lower socio-economic area.

One of the conceptual frameworks with which we began this study was that people involved in natural service delivery systems can be characterized as falling into two* categories. These categories are the Supporting Persons and the Supported Persons. A definition of each is given for the purpose of this paper:

\section{Supporting Persons: Those individuals who provide} services that support other individuals within the community. (precise definition of services, pp. 20-22).

*originally we began with three conceptual categories. The category of the "Manager", defined as those who live within. the community but do not observably provide or receive support services, was eliminated because no persons included in the study could be thus defined. 
Supported Persons: Those individuals who utilize the services of others in the community.

One of the focal points of the area which comprises st.

Francis parish is the school. Sister Mary Louise Volk, Principal of St. Francis School, was able to provide names of. 22 individuals whom she felt were representative of the categories described. She was asked to categorize them as Managers, Supporting Persons and Supported Persons. Approximately 40 hours of interviews were conducted with 15 of the 22 individuals. In order to encourage the individuals interviewed, an informally structured format (Table 1) was utilized which allowed for maximum interviewee input. Primary agenda items were designed to gather demographic information, such as name, sex, marital status and family home situation. Secondary questioning consisted of how the individual saw himself--as a supporting person or as one who receives support more than giving 1t, or as one who sees himself as a manager in the community. Further information that the interview was designed to retrieve was specific descriptions and examples concerning the type of help that was consistently provided or received. Includer in this was the attempt to see how the person interviewed felt about his role, whether or not he set aside time for, or expected to be placed in a position of helping or receiving help, or whether these were true crisis situations that warranted the utilization of his time. The answers received would allow for the determination of how important this 
position was to the person interviewed. This importance we felt would correlate with not only effectiveness or efficiency in service delivery, but also with whether or not under recurring conditions, similiar reactions would be forthcoming.

$$
\text { Pre-interview training for the interviewer was conducted }
$$

in order to maintain a consistent interviewing pattern since

a formal questionnaire was not used. No time limit was set and interviews ranged from one to two and one-half hours in length. since the interviewees exhibited varying degrees of cooperation, the tempo of the interviews fluctuated. The interviews were tape recorded and later the necessary information was transferred to $3 \times 5$ cards. These cards were divided into two categories--supporting persons and supported persons.

As many interviews as possible (12) were conducted in the interviewees' home assuring proximity, comfort and security with the surroundings. 13 interviewees were women. Three of the 15 interviewed were of minority races--one American Indian and two Mexican Americans. 11 of the interviewees could be considered in the lower socio-economic strata with the other four being in the lower middle class category.

Corbett-Terwilliger Neighborhood

The Corbett-Terwilliger neighborhood is geographically removed from the rest of Portland by major arterial streets and natural barriers. The area has a population of approximately 3000 people. It is bordered on the north and the south 
by the Ross Is land and Sellwood Bridges, and on the west and east by Barbur Boulevard and the Willamette River. It is an old community divided basically into two parts. The northern and central area is composed of a high percentage of buildings owned by absentee landlords. The overall population consists mainly of students, young people, very old people and some extremely long-term landowners with a smattering of young independent landowners. The south end consists mostly of people who have owned their own homes for a long period of time but are what would probably be considered low socio-economic status population.

One of the authors of this paper has lived in this neighborhood for over a year and in the course of that year discovered that there are people whose names keep appearing in reference to a variety of informal natural services. Contact was made with a woman who was mentioned by many in the area as providing such natural services. She acted as a primary informant and provided a list of names of people who she considered natural service deliverers in the Corbett-Terwilliger neighborhood. The pastor of the local Presbyterian church also acted as a primary informant providing names of persons he considered natural service helpers in the community. These two primary informants provided the researcher with the names of 21 people living in the neighborhood who could be described as participating in some combination of delivery or receipt of natural services. Comparison of the two lists provided a third 
list of common names. This 1 ist consisted of 10 people whose names were included in both of the primary informants' lists. Interviewing of these 10 people followed the same method as was used in the St. Francis area described above. In the process of interviewing, some cross-systems functioning became apparent: 12 additional names were added to the 1 ist as exemplary of some significant aspects of natural systems analysis. These 12 additional names completed one section of two sample natural service delivery systems selected for descriptive analysis.

\section{Analysis of Data}

The categories of services provided and received described below are those that were related in the interviews, either as directly stated by those interviewed or by references to provisions of service by general implication.

The classification of the services provided, as described by those Supported Persons interviewed, fell into the following categories:

1) Employment: receiving help in locating jobs.

2) Transportation

3) Child Guidance: can be contrasted with Child Care since it was viewed as providing the whole family with the feeling of accomplishment when the child involved altered his behavior because of success through the guidance he was receiving from an identified important member.

4) Child Care: described as providing baby-sitting type service, both in emergency and nonemergency situations. 
5) Room/Board: having someone find housing for them or receiving goods or provisions.

6) Emergency Support: receiving emergency help which consisted of neighbors helping to provide necessities following a death in the family, or when a child was 111 or any general crisis that would cause an undue hardship or immobility on the part of the individual receiving help.

7) Emotional Support: the most recurring type of support, which was described as being "someone to talk to, to trust with personal problems..." This included both crisis situations as well as non-crisis situations.

8) Emotional Guidance: differs from Emotional Support in that it seemed to be a kind of directive therapy which provided a direction or a directive type of self management, combined with supportive reassurance.

9) Religious Guidance: was viewed as a stable, religious, guidance support.

10) Companionship: described as a friend who comes to visit, offers companionship and provides transportation to and from the market, etc. This was given a special category because of the importance placed on the companionship when described.

Categories of services provided by the interviewee to others in the community are described by the supporting Persons as follows:

1) Protective Services: encompasses providing a place to go, some type of protection from aggressive family members. 
2) Referral: based on emergency and non emergency situations providing assistance to individuals who need to find some help for temporary housing, someone to care for their child or a place to go for advice.

3) Housing/Board: providing a shelter type home to those who need temporary housing.

4) Emotional Support: visiting, providing moral support, and lending a concerned "1istening ear" to members of the community.

5) Consultation/Counseling: providing individual and groups of individuals with a type of supportive counseling and reassurance.

6) Child Care: providing a place to stay for children in the neighborhood.

7) Maintenance: providing a stable influence or consistency where 1 is 1 acking, such as arguments between two factions or organizations or neighbors who are in disagreement (contrasted with group counseling because it is done on an organizational level rather than an informal or non structured group).

8) Organization Volunteer: working within a structured organization as a volunteer, such as volunteers with a school or a church organization. 
Analysis of Data for the S.E. Neighborhood

No one interviewed in the natural service delivery system described herself as being totally autonomous from other members of the neighborhood. Two of the 15 individuals interviewed described themselves as being primarily supported Persons; that is, within the neighborhood as receiving more assistance than providing ( Table 3 ). One of these individuals described receipt of assistance in nine incidences (Table 4) and providing support in only one. The other supported Person described five incidences of receiving help and one in which she was able to aid another. Both felt they were not supportive of those outside of their immediate families (but received support from non-family members).

Two individuals view themselves as being in dominant supporting roles (Table 3 ). Table 4 shows the number of incidences that these two described to the interviewer in which they provided assistance to others. The remaining 11 of the 15 interviewed described themselves as being both helpers and receivers of help.

Tables 5 and 6 indicate the frequency and types of help received by individuals in "supported persons" situations. These tables show that $83 \%$ of the people interviewed received emotional support, and that of this $83 \%$, $66 \%$ were receiving emotional support from more than one source. $82 \%$ of the supported persons received help in more than one area. The average number of services utilized was three. $54 \%$ of the 
supported persons were using child care services. In 34 situations of $47(72 \%)$, help was received from non-professional agencies, from sources other than the church, state agencies or volunteer groups.

Tables 7 and 8 refer to the frequency and types of services provided by those persons acting as supporting persons. The mean number of services provided by a single supporting person was four with seven being the highest number given by one individual. $77 \%$ of those serving in supporting roles were providing help in the areas of referral and/or emotional support. $\quad 55 \%$ provided child care services.

Analysis of Data for Corbett-Terwilliger Area

Table 9 shows the frequency of types of services received by those persons in supported roles. $80 \%$ of the people interviewed received emotional support from at least one source, and $90 \%$ received emotional support and/or emotional guidance. Al1 except one person interviewed received aid in more than one category.

Table 10 refers to the frequency and types of services provided by those persons classified as supporting persons. $90 \%$ of the people interviewed were supplying emotional support to others in the neighborhood. $60 \%$ reported incidences of providing transportation. 13 of 35 of the reported situations ( $37 \%$ ) provided emotional support or consultation. 
Combined Analysis

There were several parallels in the data of the two neighborhoods. In both areas, the services provided by the largest percentage of supporting persons were emotional support (S.E., 78\%; C-T, 90\%) and referra1s (S.E. $78 \% ; C-T, 50 \%)$. Tables 6 and 8 show the correlation in the services provided and received between the two neighborhoods. Approximately one third of the total services provided in each area dealt with emotional support and consultation (S.E., 33\%; C-T, 37\%) and two thirds dealt with daily physical survival, both crisis and non-crisis. Services received by the largest percentage of supported persons in both areas were emotional support (S.E., $82 \% ;$ C - T, $80 \%$ ), child care (S.E., $54 \% ;$ C-T, $40 \%$ ), and transportation (S.E., 36\%; C-T, 40\%).

\section{Conclusion and Discussion}

Even though distinction between supported and supporting persons has been described, in actuality the categories overlap and are not mutually exclusive. There are individuals within the two specific neighborhoods that we studied who view themselves as being both supporting and also supported. However, for the clarification of this paper, we have grouped characteristics of supported persons and supporting persons in separate categories.

Directionality of the support delivery seems to be accurately perceived by those interviewed. Supported persons did not try 
to conceal any assistance they had received from others and made no pretense of saying that they wanted to or had helped others. The supporting persons readily admitted that they saw themselves as facilitating services among those individuals that they were supporting. This support takes the form most often of providing emotional support, baby-sitting service, counseling and advice, or referring individuals to a babysitter.

In interviews with the supporting persons, it is apparent that support develops from friendships generated by reference points, mainly through children in similiar age groups. One supporting person voiced opposition to helping and trusting the "hippie" population in the neighborhood, yet considers herself an active helper with others of her attitude. The most 1 iberal supporting persons' range extends beyond peer group relationship. Neighborhood proximity seems to be also important, but the supporting persons often extend services many blocks beyond the neighborhood area. Longevity in the community contributes to trust from other members. Many individuals interviewed provide standing invitations to certain individuals in the network who find they need to come in, have a cup of coffee, and discuss their problems.

A pattern that is apparent for the supported persons is that they seem to focus their attention on their peer groups (mainly age reference groups), then on their closest friends' parents and finally on their neighbors. 
During the introductory phases of our study, it was thought that managers would see themselves as having enough strength to cope and to adjust to situations within the community without outside assistance. We could find no person in either st. Francis or Corbett-Terwilliger areas who could be considered solely a Manager. Some of the individuals interviewed, while initially perceiving themselves in this role, during the course of the interview, made references to having helped a neighbor, or extending themselves in such a way as having been of help to an individual. Even those described as potential managers by Sister Mary Louise or by the primary informants in the Corbett-Terwilliger area, during the course of the interview mentioned providing support in some way to other members of the community.

Another category was also discovered during the research time period. The description is a difficult one, but a definition was provided by at least one of the individuals interviewed. This term, the "User", is an individual who is viewed as one who is agency- and community- "wise;" that is, one who utilizes whatever means possible to cope within the community with no intention of repaying any of the support offered, depending on help and expecting the services to be provided free of responsibility. None of those interviewed would fit into this category, but there were references during interviews to this type of individual. For the most part, these people are recognized as being the "long-haired" young transients of the 
neighborhood who have seemingly no intention of settling down in the community or taking responsibility for its development. It is possible that the "User" category is a perception of another intrusive group by those interviewed. For this study there is not sufficient data to further explore the "User" category.

Narrative

We have discovered in the process of identifying and defining natural service delivery systems that some of the essential aspects of those systems cannot be exclusively determined through an analysis of data provided in the interviews. Mutuality seemed to characterize almost all of the relationships within the helping networks. We have, therefore, selected as examples of this mutuality, two systems from Corbett-Terwilliger to describe in a narrative fashion. Our intention is to share some anecdotal evidence in hope that a narrative will come closer to defining some elements which cannot be included statistically. The two systems, "C" and "K", are drawn from different parts of the neighborhood with differing population composition. These narratives are constructed from the interviewers' notes, and are therefore the interviewer's perception of the situation.

"C"

"C" is a 32-year-old working housewife and mother of three children. She has lived in the Corbett-Terwilliger 
neighborhood for six years and during those six years has become active in many community groups and city wide issues. She lives in the southern section of the neighborhood and her husband owns several pieces of property there. "C" discovered upon moving to the area that access to the networks of service delivery and social acceptance was limited. There existed a "rite of entree", an apprenticeship process, whereby new residents were not allowed participation until persons in the network described were satisfied that they could be trusted.

After an informal "apprenticeship" period of nearly two years, "C" was able to gain access to some of the existing systems as wel1 as opportunity to develop new systems. "C" had begun teaching sunday school at the local church, and it was through that medium that her system began to develop. She met an older woman, "L", who became her friend and confidant. "L" has been the single most identifiable person in helping "C" live within the neighborhood. In the course of the next few years, "C" met " $T$ ", an older woman of the identifiable GermanAmerican group in the southern part of the area. " $C$ " and " $T$ " became friends through the Cub Scout den when "C" became the den mother. " $T$ " provides child care and teaches sewing to "C". "C" provides general emotional support and encouragement as well as specific advice to help cope with daily problems. The position that "C" holds in the natural service network (Diagram 1) is almost perfectly balanced. She described as many people who support her as of whom she is supportive. Her 
major thesis recounted in the interviews is that without all of the people she turns to and in turn who look to her, she would not be able to function. She reported that those first years in the neighborhood were very difficult because she felt without support. As "A" looks to her for support (Diagram 1), she looks to "L" for support. This concept of mutuality was an essential aspect of all of the functioning natural service delivery systems discovered in the Corbett-Terwilliger area.

Services provided historically by family members were found to be now provided by natural systems. "C" reported that many of the services provided for her act, in effect, as replacements for services that at one time were appropriate roles for family members. She said that her grandparents had once done for her mother what the various members of her natural service delivery system are called upon to do now. Inversely, she provides services to older neighbors, "T" specifically, which would have at one time been an appropriate function for children or grandchildren.

The local church in the southern section of the neighborhood acts as a resource center around which many natural service constellations revolve. It was at the church that " $C$ " met " $L$ " who at that time was working with one of the retarded children from the neighborhood. "C" reports having an immediate rapport with "L". "C" characterized her relationship with "L" as one of love and honesty. "L" has an enormous capacity for love, but tells the truth as she sees it. She is, however, nonthreatening and wise. "C" calls her "my foster mother". 
Support System for "C"

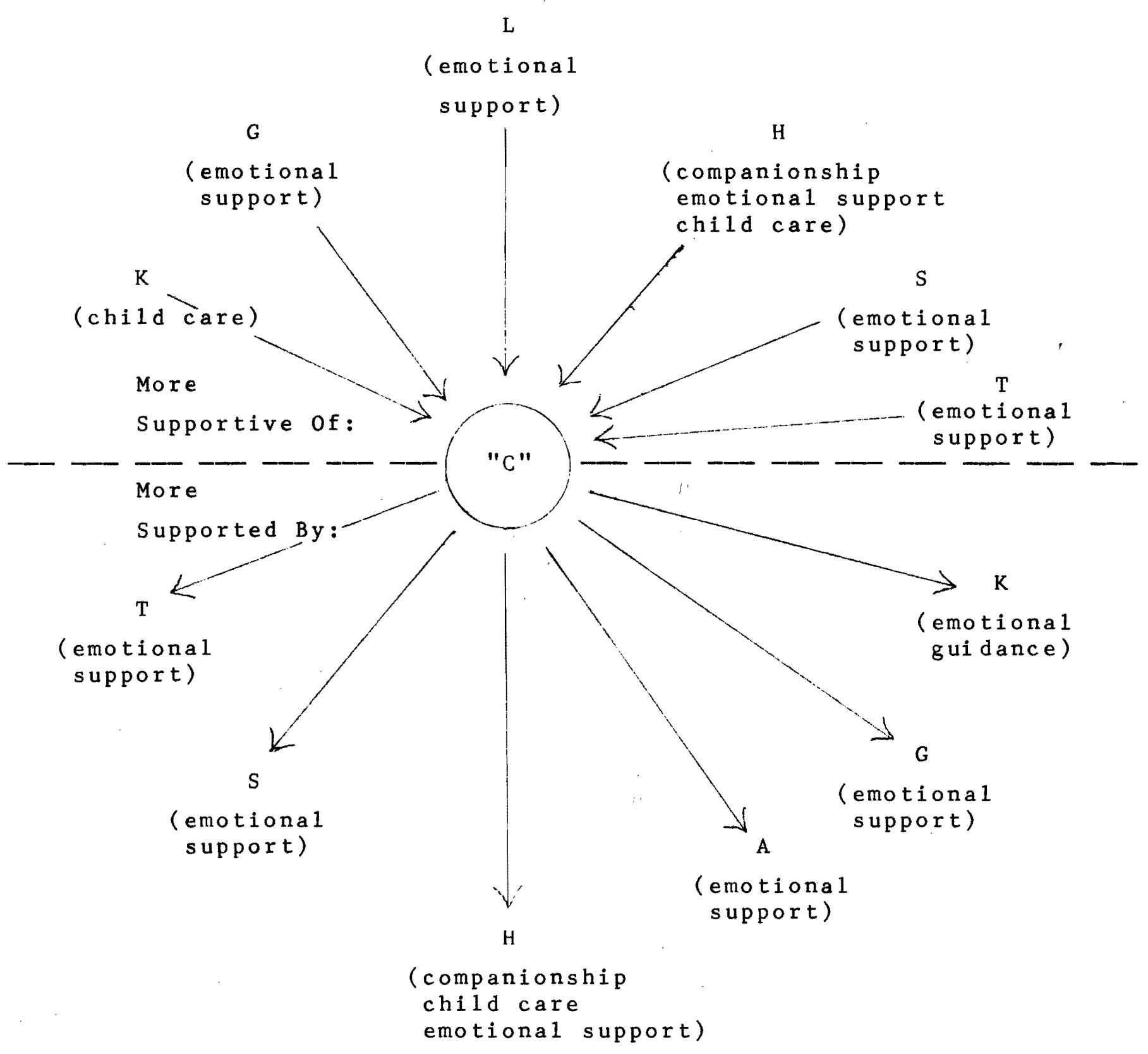

DIAGRAM 1 
"K"

"K" is a 24-year-old housewife, mother of two, who lives in the central section of the Corbett-Terwilliger neighborhood. She has 1 ived in the area approximately three years. In this period of time she has become part of a natural service delivery constellation which differs from others in the study only in the rapidity with which it developed and with the dramatic inclusion of members of groups which are usually considered exclusive. This system, like many others studied, does not necessarily center on any particular person, but "K's" position in it tends to be relatively static and thus lends itself to analysis.

"K" seems to be more supportive of than supported by her section of the constellation (Diagram 2). Two members of the network look to her as almost a sole source of support. One member denoted as "Ch" had an especially interesting story to te 11 .

Both "Ch" and "K" live in a part of the neighborhood which can be demographically described as consisting of two major groups of people, each with significant sub-groups. Most of the people in this part of the neighborhood are either old or young. There are large numbers of young "hips" who have settled in this area and many of them live in the immediate vicinity of "Ch". There are also large numbers of the Italian and Jewish working people who originally built old southwest 
Portland into a culturally and spiritually rich community. The two groups, the young "hip" and the old "ethnics", have always functioned as relatively alien influences on one another.

"Ch" was born in the extreme northern section of Italy in 1891. She moved to America in 1912, and to old south Portland in 1917. During those 56 years, she has witnessed many changes in the world, from Franz Josef to Richard Nixon; in the city, from the Barbur trolley car to the Marquam Bridge; and in Corbett-Terwilliger, from the Italian workers walking up the hill from Carothers Mill to long haired young smoking pot on the street corners and in the park. When the young, long haired people began appearing in the city in the middle " $60^{\prime} \mathrm{s}$, "Ch" felt more of a sense of confusion than at almost any other time in the twenty years since her husband had died. She was old, alone and the life styles of these young people were totally alien to anything that "Ch" had known. "K" and her husband represented many of the things that "Ch" feared. The man was long haired, looked strange and had a casualness to many of the principle virtues held by "Ch", such as work. The original meeting of " $\mathrm{Ch}$ " and "K" took place as a result of "K's" search for a baby sitter for her two children. The meeting came about through the efforts of a community agent employed by the neighborhood council. All of the parties involved were a bit skeptical. "Ch" proved 
a bit too old to adequately care for "K's" children, but a very important relationship developed out of her genuine efforts. This relationship is almost two years old at present and consists of weekly associations between the two people. "Ch" looks to "K" as a very important source of companionship and emotional support, as well as transportation. "K" looks to "Ch" as a source of much wisdom and insight. They both articulate their mutual feelings of affection, appreciation and the real things one provides to the other.

We believe that these two cases provide an example of what is meant by the concept of mutuality and how each individual within a constellation seems to provide and/or receive help within their constellation. In both of the neighborhoods studied, mutual relationships such as the two described were verbalized and can be considered a necessity in the continuance of the sharing association of a constellation. 


\section{Support System for " $K$ "}

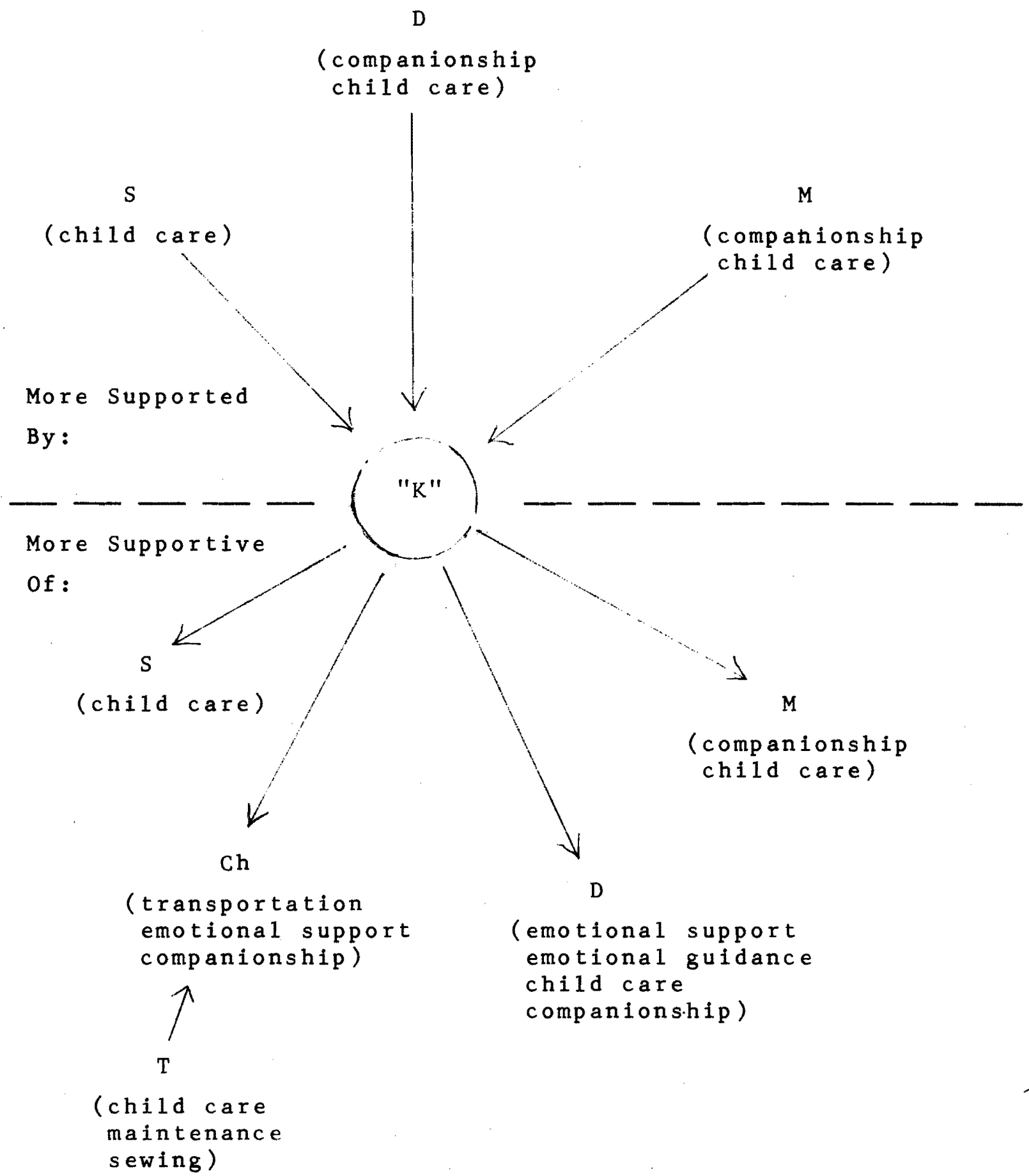




\section{Other Findings}

There are other circumstances within the systems that were not revealed in statistical data that we feel need to be mentioned in order to better understand the communities studied. Those topics not exemplified by data are the national and ethnic minorities within the communities studied, religious influences, processes of acceptance, natural crisis intervention helpers, and outsiders within a natural system.

There are some major, long-term natural systems in the Corbett-Terwilliger neighborhood found among the national and ethnic sub-groups, such as German and Italian families. These sub-groups were most difficult to describe because access to the various members was impossible for the researcher to gain. These systems were described by other members of the community who were aware of the1r existence. In the S.E. neighborhood, Mexican-Americans and native Americans were not impossible to gain access to interview. The minority individuals, however, were hesitant in discussing either helping others or receiving of assistance. During the interviews they discussed family ties more than neighbors or school contacts. Even though others outside of the minorities' immediate families told of having helped them, those minorities interviewed, when questioned in this regard, readily admitted being assisted, but emphasized the family support. 
$89 \%$ of those interviewed in the St. Francis area were Catholic. This may have influenced the predominance of an attitude of viewing children as a measure of parental success in one form or another. That is, the number of children seems to be equated with the parents' feelings of success. There was a consistent reference to family and number of children. It is our subjective feeling that religion may also influence the family attitudes in the Corbett-Terwilliger neighborhood.

Acceptance in the neighborhood takes the form of a personal commitment, which could take the form of purchasing a house, longevity in the neighborhood or involvement in community activities. Purchasing a home is seen by other residents interviewed as the supportive commitment one can make to a community. Since the transient condition of the neighborhoods is viewed as a major cause of their deterioration, there is a buffer time period before helpers will extend their friendship by invitations to informal get-togethers, invitations to school, church or children's organizations (such as girl and boy scouts). This transitional or buffer period is a time when the long term resident can establish a mutual trusting relationship. This period seems to last from two to five years depending on how out-going the new member has been.

It is apparent from the interviews that there are individuals who are viewed as crisis intervention supporting helpers. There appear to be at least two ways of viewing the mobility 
of these persons. The crisis intervention helper may possibly be a member of a different system who is able to cross system lines in order to aid in a crisis situation, or may, in fact, be less visible in the community except when a crisis occurs. An example of the crisis supporting person was described by an individual who had received help from one such source. The person interviewed, who had fallen and broken her foot, met for the first time a woman living one block away who rushed over offering several types of assistance from baby-sitting to cooking meals for the family. When told everything was under control, the neighbor left and has not seen or talked with the injured woman since. The two theories suggested above are offered as possible explanations for her sole appearance in the systems that were investigated.

There was one woman interviewed who was unique to the study by the fact that she was viewed by a primary informant as being a supported person within a natural system, yet she did not view herself as being part of any system. She was an individual who receives only support with no reciprocation and was totally passive about her present situation. She was not concerned with helping others. This was a woman who had.lived under two agencies' guidance having four caseworkers guiding her in training, housing and welfare support. Yet the concern utmost expressed in the interview was concern. for self, rather than family, friends or roommates. This woman is given as an example since there is a possibility of being viewed as a supported person but not perceiving oneself as being part of a system. 


\section{Summary}

The basic analyses of data and experiences from St. Francis and Corbett-Terwilliger leads us to conclude that natural service delivery systems do exist. Not only do they exist, but there are five major concepts that we discovered in the course of researching toward identification and definition of natural service delivery systems within the specific areas studied. These concepts are: 1) the principle of mutuality/ balance, 2) the principle of survival, 3) the concept of "ethnicity" and its impact on the development of certain natural service delivery systems, 4) the relationship between contemporary natural service delivery systems and past functions of family, and 5) the principle of apprenticeship/protocol.

A pattern in the two areas researched is that as people support, so in turn are they usually supported. The function of people who support being conversely supported is essentially one of balance. The principle of mutuality may be illustrated by the "C" case. As "C" supports "A", so she in turn is sup-" ported by "L". She articulates these dynamic interactions as a necessary component to survival, both for herself and for the constellation. A person may reciprocate services received, and may repay with other services. This concept may be acted out with one person or a completely different person. The diagrams used to illustrate the " $C$ " case and the "K" case show the possibilities of this concept as they affect these two constellations. In other words, a person who is supported 


\section{1}

may, in some way, support the person who initially supported him, and he may extend services to another member of the constellation. These factors combined allow for a sense of balance which means that these people can "make it" from day to day.

In this sense and in this manner, the first two concepts, mutuality/balance and survival, interact as basic dynamics. Our data indicate that most services (about two-thirds, with only one-third of the total services dealing with emotional support and consultation) are provided basically to address the end of survival.

The third concept, "ethnicity", is basically speculative, but our 1 imited experience indicates that ethnic background constitutes the basis for certain natural service delivery systems. The German-Americans in Corbett-Terwil11ger, the Chicano and native American families in St. Francis all developed systems within their own ethnic or national groups. Ethnic groups developed constellations out of the neighborhood but within their own nationality. We found these groups particularly difficult to study.

The fourth principle, systems as fulfilling past functions of the family, is essentially one which was articulated from time to time in the study and which seems to the researchers as one worthy of note. Numerous persons interviewed indicated that they saw many of their support and supported efforts as services which at a point in the not-too-distant past were 
appropriate functions for the immediate family as it was conceived then. "C", for example, said that in the "old days" her parents would have cared for her children as " $T$ " does now. " $T$ " would have been taken shopping by her children as "C" does now. "C" would have been taught sewing by her mother instead of by " $T$ ". We may speculate that sociological changes in the family may influence the character and composition of natural service delivery systems.

The final concept, apprenticeship/protocol, may best be illustrated by the recurrent statements from interviewees in both S.E. and Corbett-Terwilliger that the total systems to which individuals belonged took a considerable period of time to develop. All of the systems described in this study took at least two years to fully develop. "C" in Corbett-Terwilliger clearly articulated that there is both a space and a time dimension to enter into those existing natural service delivery systems that we identified and to develop new natural service delivery systems. We found that buying a house in the neighborhoods studied seems to be a primary criterion for acceptance. People who are not buying houses must at least live in one as opposed to an apartment complex. Common churches, children allending the same school, and even number of children were discovered as other primary criteria. 


\section{Implications}

The following implications are drawn from the two specific neighborhoods and the systems within those neighborhoods that were identified and studied. In order to further develop the concept of the natural neighbor, certain considerations of the procedure of identifying and defining the natural neighbor are mandatory. It becomes a more manageable task when the Social Worker makes a point of gaining knowledge of not only the area but of the children of many of the families who are in the community. Since this was a participant-observer outlined method of reporting, the interview techniques were patterned after this methodology. However, entree into the individual homes was gained mostiy by explaining not only the nature of the project, but also by the connection with other contributing organizations. Thus, in order for future investigations to allow for open and free conversation, the social Worker should represent, or be part of," a trusted fixture of the community, be it school, church, etc. Many studies have been built around lower socio-economic communities, thus it is paramount that the interview be conducted strictly as investigative, and that no expectations, no matter how subtle, be given as to results of the study.

The supporting individuals, as well as those who rely on support, often find no one to turn to for particular needs of their own. Thus, in many respects, the interviews serve two purposes: information for the interviewer and objective feedback for those being interviewed. 
What does this mean to Social Work and to the Social Worker? It means that we need to develop a way of thinking about natural service delivery systems and that way of thinking has implication for interaction with and utilization of these systems. The key to a usable conceptual framework by which approaches to natural service delivery systems become real to practicing Social Workers lies in the term "resource". We usually conceive of resources as formalized units of service delivery. The possibility exists that individuals might share the term resource with provider agencies. Instead of limiting our problem solving/resource analysis abilities to child care agencies, public health nursing, and welfare services, we might, if we knew, begin to consider "T" or " $\mathrm{C}$ " as other resources existing on our "beat". This ability to conceptualize natural service delivery systems as resources involves a dramatic revision of an unstated practice principle. We say that we begin where the client is, that we are not judgmental, that we allow a searching for self fulfillment, but we often practice as teachers and experts. In the realm of natural service delivery system we must begin to function as learners. The realm of natural service delivery system providers is, after all, theirs and not ours. 
XIGNGdd 


\section{INTERVIEW DESIGN}

I. Introductions

II. Purpose stated

III. Questions designed to obtain general information of the person interviewed concerning:
A. Attitudes about himself
B. Attitudes about his family
C. Attitudes about his 1 ife style
D. Attitudes about his relationship with others in close proximity
E. Attitudes about his relationship with relatives in the area, if any
F. Attitudes about his existing community in general

IV. Questions designed to collect specific information

A. Questions designed to allow person to express examples of situations mentioned in "warm up" time

1. Questions designed to encourage specific examples organized in order of most recent (either supported or supporting) and working in inverse order gathering as much information about situations that the person is able to remember

2. Questions designed to organize the examples so that they are even more specific as to supporting and supported relationships to obtain more specific information and impressions

B. Questions as to whether or not the person organizes her time to add more support, or if the situations are accidental

C. To collect names of others in the neighborhood who act as key persons in these functions. 


\begin{tabular}{|c|c|}
\hline \multicolumn{2}{|c|}{ CLASSIFICATION OF } \\
\hline \multirow[b]{2}{*}{ Services Provided by } & SERVICES \\
\hline & Services Received by \\
\hline Supporting Persons & Supported Persons \\
\hline Protective Service & Employment \\
\hline Reférral & Transportation \\
\hline Donations & Housing \\
\hline Housing/Board & Provisions \\
\hline Emotional Support & Emergency Support \\
\hline Consultation & Emotional Support \\
\hline Child Care & Child Care \\
\hline Maintenance & Emotional Guidance \\
\hline \multirow[t]{4}{*}{ Organization Volunteer } & Companionship \\
\hline & Child Guidance \\
\hline & Religious Guidance \\
\hline & \\
\hline
\end{tabular}

TABLE 2 


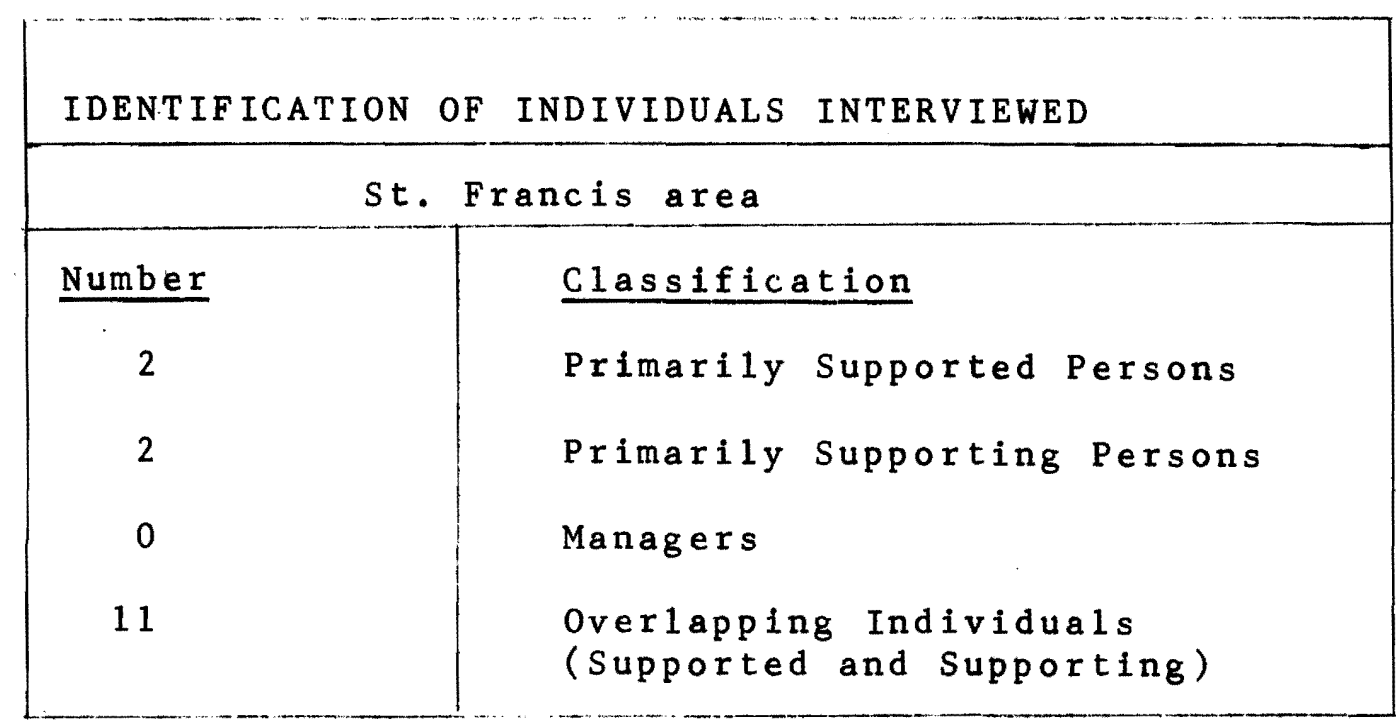

TABLE 3

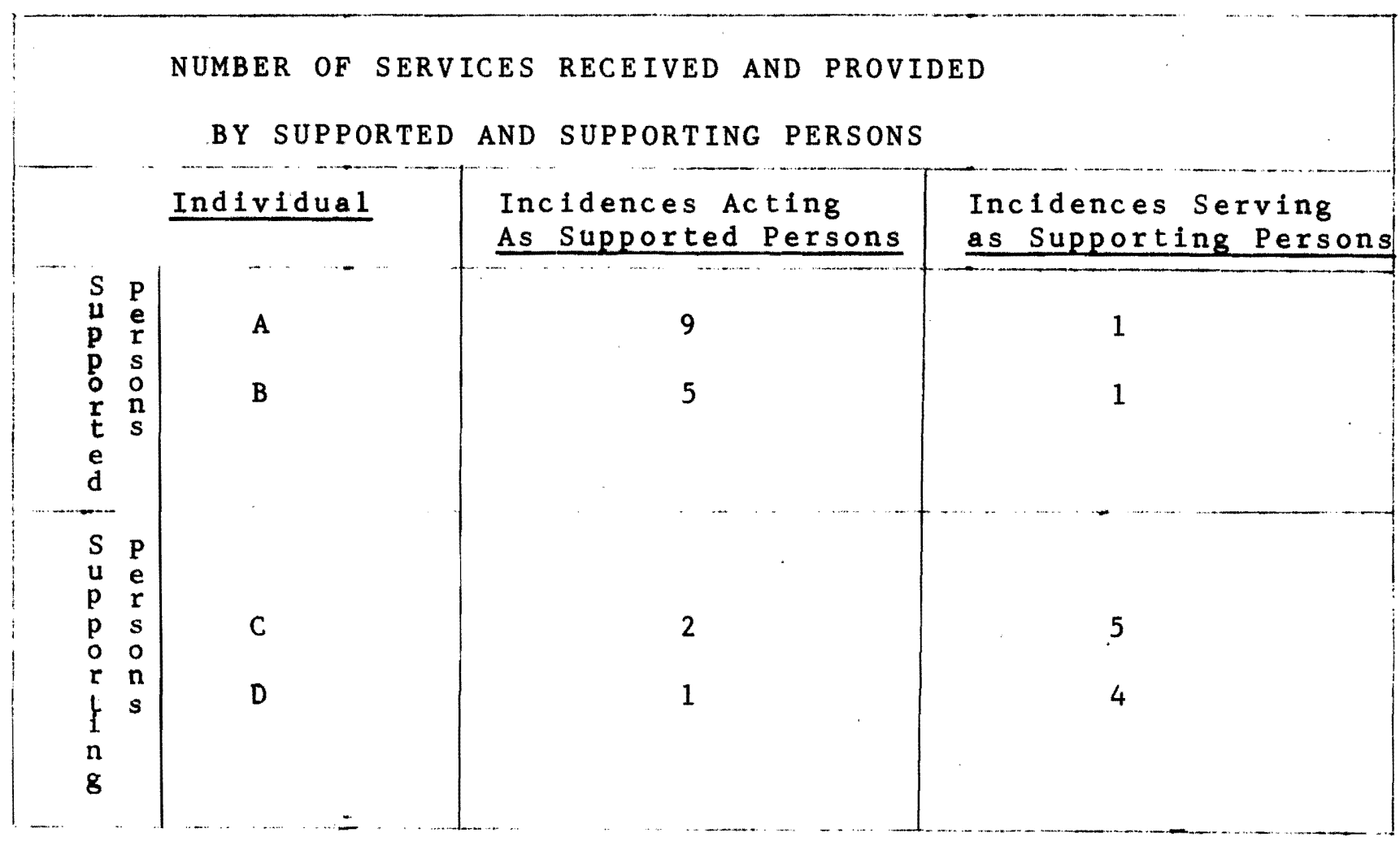

TABLE 4 


\begin{tabular}{|c|c|c|c|c|c|c|c|c|c|c|c|}
\hline & & \multicolumn{9}{|c|}{$\begin{array}{l}\text { SERVICES RECEIVED } \\
\text { St. Francis area }\end{array}$} & \\
\hline $\begin{array}{r}\text { Supported } \\
\text { persons }\end{array}$ & 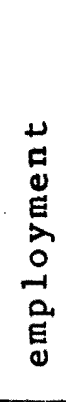 & 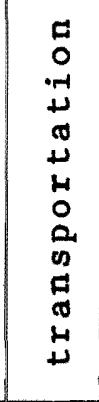 & 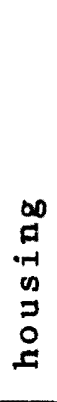 & $\begin{array}{c}n \\
0 \\
0 \\
0 \\
0-1 \\
0 \\
-1 \\
0 \\
0 \\
0 \\
0\end{array}$ & 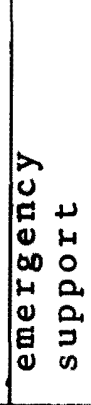 & 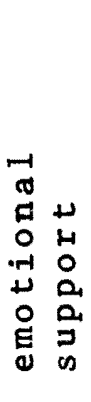 & 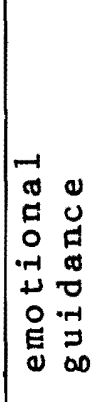 & $\begin{array}{cc}0 & \\
J & 0 \\
0 & 0 \\
-1 & 0 \\
00 & 0 \\
-1 & 0 \\
-1 & 0 \\
0 & -1 \\
0 & J \\
H & \infty\end{array}$ & 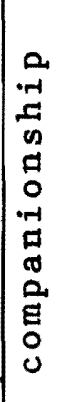 & 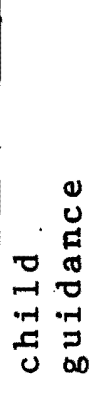 & 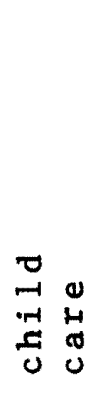 \\
\hline $\mathrm{A}$ & & $X$ & & $\mathrm{X}$ & $X$ & $\mathrm{XX}$ & $X$ & & & & $\mathrm{X}$ \\
\hline $\mathrm{B}$ & $\mathrm{X}$ & $\mathrm{XXX}$ & & $X$ & & $\mathrm{X}$ & & & & & \\
\hline C & & & & & $\mathrm{X}$ & $\mathrm{XX}$ & $X$ & & & & $X$ \\
\hline D & $X$ & $\mathrm{X}$ & $X$ & & & & $\mathrm{X}$ & & & & \\
\hline $\mathbf{E}$ & & & & $X$ & & $\mathrm{X}$ & & & & & $\mathrm{X}$ \\
\hline $\mathbf{F}$ & & & & & $\mathrm{X}$ & & & & & & \\
\hline G & & & & & $\mathrm{X}$ & $\mathrm{XX}$ & & & & $X$ & $\mathrm{XX}$ \\
\hline $\mathrm{H}$ & & & & & & $X$ & & & & & \\
\hline$I$ & & & & & & $\mathrm{XX}$ & & & & & \\
\hline $\mathbf{J}$ & & & & & & $\mathrm{XX}$ & & & & & $\mathrm{XX}$ \\
\hline $\mathrm{K}$ & & $X$ & & $\mathrm{X}$ & & $\mathrm{XXX}$ & & $\mathrm{X}$ & $X$ & & $\mathrm{X}$ \\
\hline $\begin{array}{l}\text { Total } \\
\text { Persons } \\
\text { Reporting }\end{array}$ & 2 & 4 & 1 & 4 & 4 & 9 & 2 & 1 & 1 & 1 & 6 \\
\hline
\end{tabular}

Frequency of Help Received by Supported Persons

$$
x=\text { One incident reported }
$$

TABLE 5 


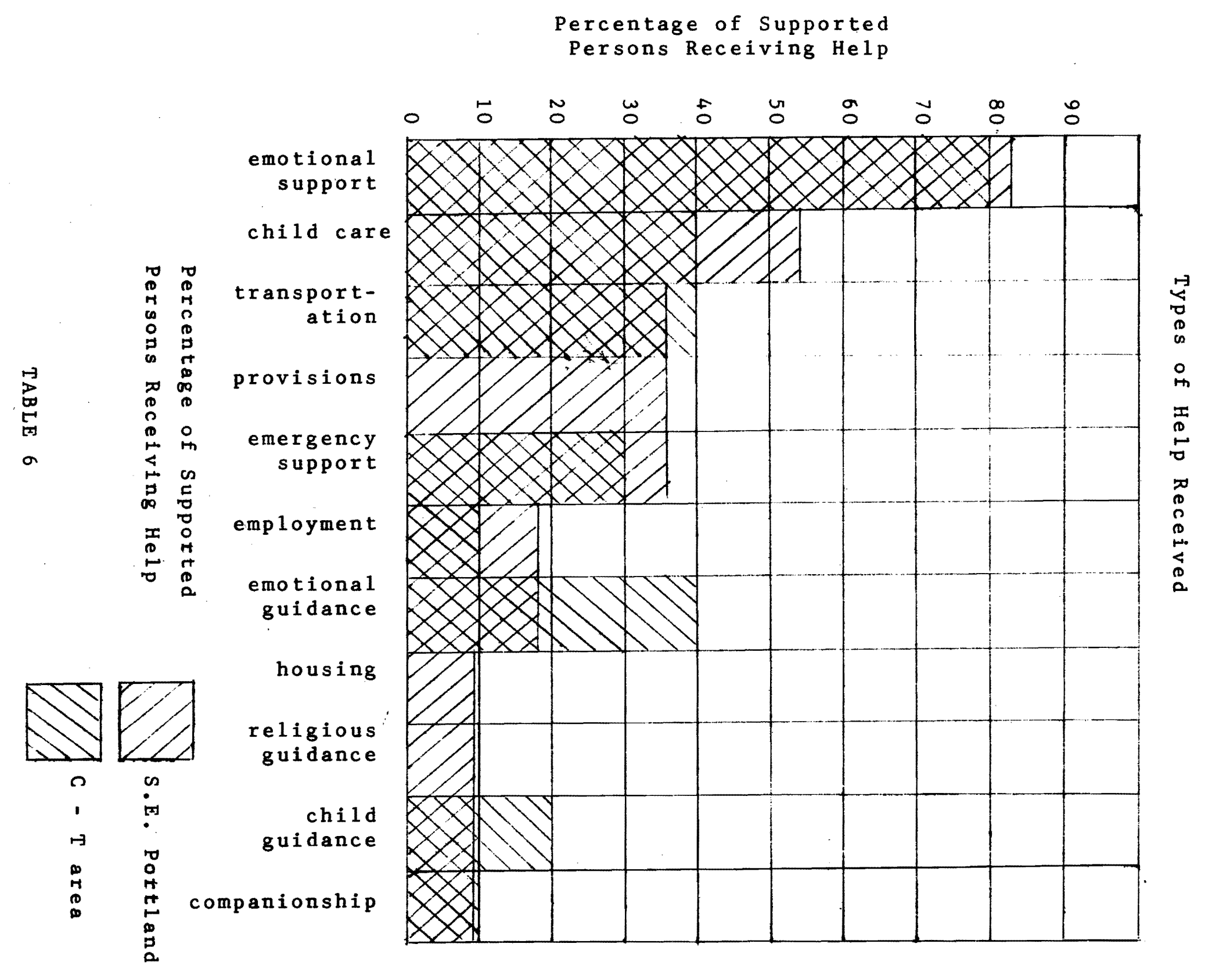




\section{SERVICES PROVIDED}

St. Francis area

\begin{tabular}{|c|c|c|c|c|c|c|c|c|c|}
\hline$\left\{\begin{array}{c}\text { Supporting } \\
\text { Persons }\end{array}\right.$ & 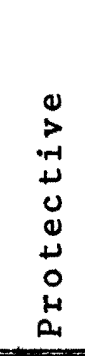 & 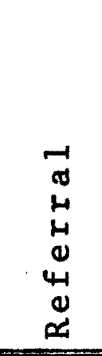 & $\begin{array}{c}n \\
\vdots \\
0 \\
0 \\
ت \\
0 \\
0 \\
\vdots \\
0 \\
0 \\
\end{array}$ & 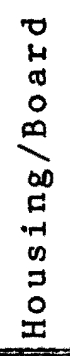 & 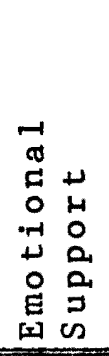 & $\begin{array}{l}1 \\
0 \\
0-1 \\
+1 \\
0 \\
\pm \\
-1 \\
3 \\
0 \\
0 \\
0 \\
0 \\
0\end{array}$ & $\begin{array}{l}0 \\
\stackrel{0}{0} \\
0 \\
0 \\
0 \\
-1 \\
ت \\
0\end{array}$ & 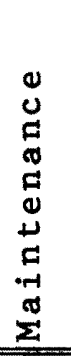 & 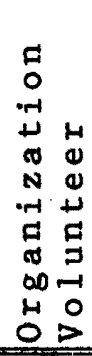 \\
\hline A & $\mathrm{X}$ & $\mathrm{X}$ & & $\mathrm{X}$ & $\mathrm{X}$ & $X$ & $\mathrm{X}$ & & \\
\hline B & $\mathrm{X}$ & $x$ & $\mathrm{X}$ & $\mathrm{X}$ & $\underline{x}$ & $\mathrm{X}$ & & $x$ & \\
\hline C & $\mathrm{XX}$ & $\mathrm{XXX}$ & & $\mathrm{X}$ & $\mathrm{X}$ & & $\mathrm{X}$ & & $\mathrm{x}$ \\
\hline D & & $\mathrm{X}$ & $\mathrm{X}$ & & $\mathrm{X}$ & $\mathrm{X}$ & & $\mathrm{X}$ & \\
\hline$E$ & & $\mathrm{XX}$ & & & $\mathrm{XX}$ & & $\mathrm{X}$ & & \\
\hline$F$ & & $\mathrm{X}$ & & & $\mathrm{X}$ & & & & \\
\hline$G$ & & & & & & & & & $\mathrm{X}$ \\
\hline $\mathrm{H}$ & & & & & & & $\mathrm{x}$ & & $\mathrm{X}$ \\
\hline$I$ & $\mathrm{X}$ & $X$ & & $\mathrm{X}$ & $\mathrm{X}$ & $\mathrm{X}$ & $\mathrm{X}$ & & \\
\hline $\begin{array}{l}\text { Total } \\
\text { Persons } \\
\text { Reporting }\end{array}$ & 4 & 7 & 2 & 4 & 7 & 4 & 5 & 2 & 3 \\
\hline
\end{tabular}

HELP GIVEN BY SUPPORTING PERSONS

$X=$ one incidnet reported

TABLE 7 


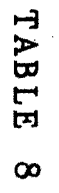

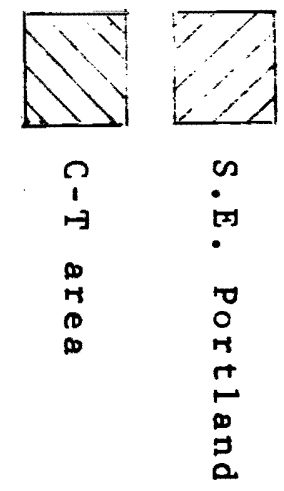

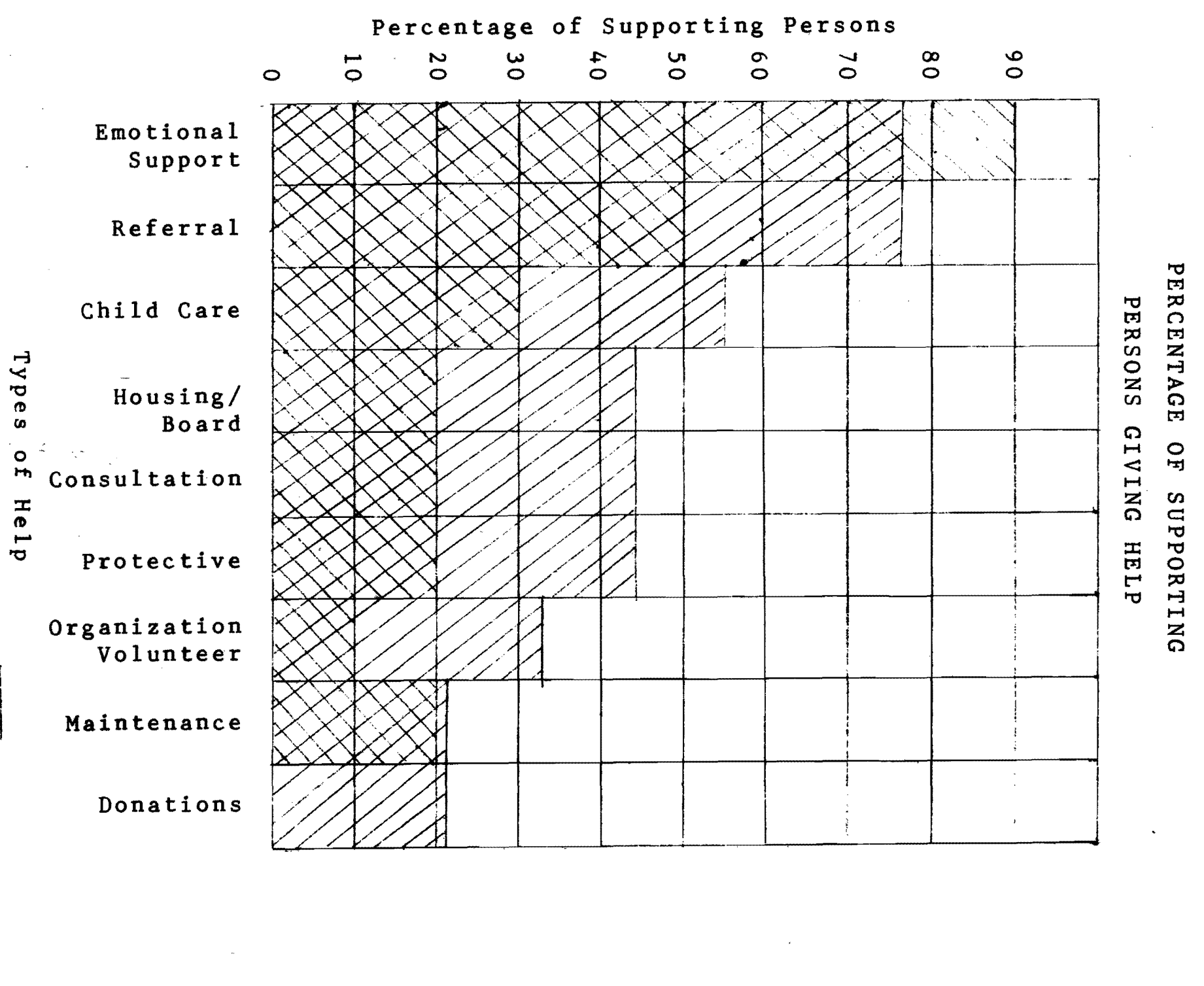




\section{37g}

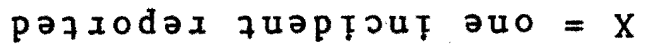

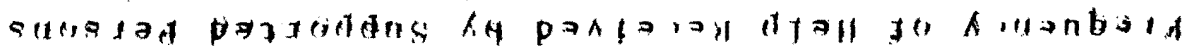

\begin{tabular}{|c|c|c|c|c|c|c|c|c|c|c|c|}
\hline 7 & $z$ & I & 0 & 7 & 8 & $\varepsilon$ & 0 & 0 & 7 & I & 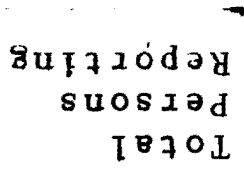 \\
\hline & & $X$ & & & $\mathrm{X}$ & & & & $X$ & & $\Gamma$ \\
\hline & & & & & $X$ & $x$ & & & & & I \\
\hline & & & & & $\mathrm{X}$ & $\mathrm{X}$ & & & $\mathrm{X}$ & $x$ & H \\
\hline & & & & $\mathrm{X}$ & & & & & & & $\rho$ \\
\hline$X$ & & & & & $\mathrm{X}$ & & & & & & $A$ \\
\hline $\mathrm{X}$ & $x$ & & & $\mathrm{X}$ & $\mathrm{X}$ & $\mathrm{X}$ & & & & & $\exists$ \\
\hline & & & & & $\mathrm{X}$ & & & & $\mathrm{X}$ & & a \\
\hline$X$ & $X$ & & & & & & & & & & 5 \\
\hline & & & & $X X$ & $\mathrm{X}$ & & & & & & g \\
\hline $\mathrm{XX}$ & & & & $X$ & $\mathrm{XX}$ & & & & $X$ & & $\forall$ \\
\hline $\begin{array}{l}\Omega \\
2 \\
2 . \\
2 \\
0 \\
0 \\
0 \\
0 \\
0 \\
0\end{array}$ & 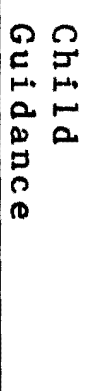 & 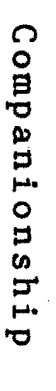 & 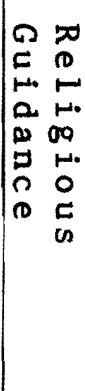 & 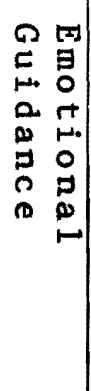 & 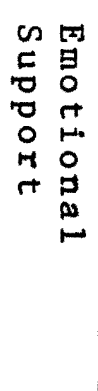 & $\begin{array}{ll}0 & 1 \\
5 & 9 \\
0 & 0 \\
0 & 1 \\
0 & 0 \\
H & 0 \\
r & 0 \\
0 & 0 \\
4\end{array}$ & $\begin{array}{l}0 \\
0 \\
0 \\
0 \\
4 \\
1 . \\
0 \\
0 . \\
0 \\
0 \\
0 \\
0\end{array}$ & $\begin{array}{l}\text { T. } \\
0 \\
5 \\
6 \\
0 \\
3 \\
0 \\
0\end{array}$ & 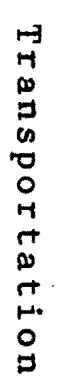 & 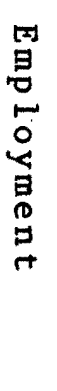 & $\begin{array}{r}\text { suosiad } \\
\text { pazIoddns }\end{array}$ \\
\hline
\end{tabular}

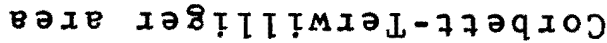

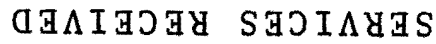


SERVICES PROVIDED

Corbett-Terwilliger area

\begin{tabular}{|c|c|c|c|c|c|c|c|c|c|c|}
\hline $\begin{array}{l}\text { Supporting } \\
\text { Persons }\end{array}$ & $\begin{array}{l}0 \\
0 \\
.1 \\
+1 \\
0 \\
0 \\
0 \\
0 \\
0 \\
0 \\
0\end{array}$ & 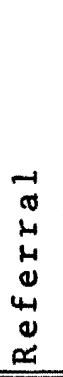 & 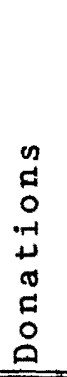 & 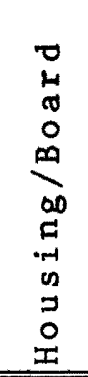 & 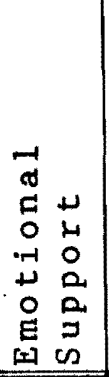 & 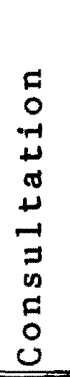 & $\begin{array}{l}0 \\
0 \\
0 \\
0 \\
0 \\
0 \\
-11 \\
0 \\
0\end{array}$ & 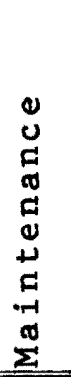 & 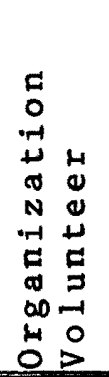 & 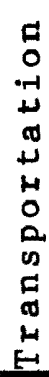 \\
\hline A & $\mathrm{X}$ & $X$ & & & $\mathrm{XX}$ & & & & & $\mathrm{X}$ \\
\hline B & & $\mathrm{X}$ & & $X$ & $\mathrm{X}$ & & & & & $\mathrm{X}$ \\
\hline C & & $\mathrm{X}$ & & & $\mathrm{X}$ & $\mathrm{X}$ & & & & $X$ \\
\hline D & & $\mathrm{X}$ & & & $\mathrm{X}$ & $\mathrm{X}$ & & & & $\mathrm{X}$ \\
\hline $\mathrm{E}$ & $\mathrm{X}$ & $x$ & & $\mathrm{X}$ & $\mathrm{X}$ & & & & & $\mathrm{X}$ \\
\hline $\mathrm{F}$ & & & & & $X$ & & $\mathrm{X}$ & & $\mathrm{X}$ & \\
\hline G & & & & & $X$ & & $\mathrm{XX}$ & & & \\
\hline $\mathrm{H}$ & & & & & $X$ & & $\mathrm{X}$ & & & \\
\hline I & & & & & & & & $X$ & & \\
\hline $\mathrm{J}$ & & & & & $\mathrm{XX}$ & & & $x$ & & $\mathrm{X}$ \\
\hline $\begin{array}{l}\text { Total } \\
\text { Persons } \\
\text { Reporting }\end{array}$ & 2 & 5 & 0 & 2 & 9 & 2 & 3 & 2. & 1 & 6 \\
\hline
\end{tabular}

HELP GIVEN BY SUPPORTING PERSONS

$$
X=\text { one incident reported }
$$


XHd $\forall$ YDOITgIg 


\section{B I BL IOGRAPHY}

Anderson, Dorothy B, and McClean, Lenora J, Identifying Suicide Potential. New York: Behavioral Publications, Inc., 1971 .

Bergman, Robert. "Navajo Psychotherapy," Time, June 12 , 1972 .

Caplan, Gerald. "Support Systems" unpublished. Keynote address to Conference of Department of Psychiatry, Rutgers Medical School and New Jersey Mental Health Association, June 8,1972 , Neward, New Jersey.

Chatterjee, P. "Community in Social Sciences and Social Work." Indian Journal of Social Work. 31 (2), 125-133.

Churchman, C. West. The Systems Approach. New York: Dell Publishing Co., 1968 .

Collins, A. H. and Watson, E. L. "Exploring the Neighborhood Family Day Care System," Social Casework. 1969, 50 (9), $527-533$.

Curtis, R. L. and Zurcher, C. A. Jr. "Voluntary Associations and the Social Integration of the Poor." Social

Problems. 1971,18 (3), 339-357.

Duh1, L. J. (ed.). The Urban Condition. New York: Basic Books, 1963 .

Dumont, Matther P. "Tavern Culture: The Sustenance of Homeless Men." American Journal of Orthopsychlatry. $1967,37,938-945$.

Edwards, M. G. and Schmidt, E. R. "Downtown in the Office." Social Casework, 1971,52 (10), 634-642.

Fischer, E. H. "College Students as Companions to Long Term Mental Hospital Patients: Some Considerations." Journal of Consulting and Clinical Psychology. 1970, $35(3), 308-310$.

Gans, H. The Urban Villagers. New York: Free Press, 1962.

Hobbs, N. "Mental Health's Third Revolution." American Journal of Orthopsychiatry. $1964,34,822-8 \overline{33}$. 
Irwin, Theodore. "They Tell It to Bartenders and Beauticians." Parade, Sunday oregonian. July 30 , 1972 .

Jeffers, Camille. Living Poor: A Participant Observer Study of Choices and Priorities. Ann Arbor, Michigan: Ann Arbor Publishers, 1967.

Junker, Buford. Field Work. University of Chicago Press: Chicago. 1962 .

Levitt, L. I., Brown, W. H. Lee, and Lewars, M. H., "A Model Project in Community Mental Health: Consultation to an Urban Welfare Center Serving a Single-Room occupancy Hotel." Community Mental Health Journal. $1968,4(6), 492-498$.

Liebow, Elliot. Tally's Corner. Boston: Little, Brown and Co., $196 \overline{7}$.

Maas, H. S. "Children's Environments and Child Welfare." Child Welfare, 1971,50 (3), $132-145$.

Marsha11, Carlton D. and Finan, John L. "The Indigenous Nurse as Crises Counselor." presented at the American Association of Suicidology, Third Annual Conference, San Francisco, March 22-23, 1970.

Miller, S. M. and Rein, M. "Change, Ferment and Ideology in the Social Services." Read at Council of Social Work Education, Toronto, January, 1964 .

Pearl, A. and Riessman, F. New Careers for the Poor. New York: Free Press, 1965.

Phillips, M., Goldman, J. and Kogan, L. S. "The Use of Family Day Care by AFDC Recipients." Public Welfare, $1971,29(2), 206-208$.

Potsubay, Richard. "\$100-a-Year Therapists." unpublished.

Reiff, Robert and Riessman, Frank. The Indigenous Nonprofessional. New York: Behavioral Publications, Inc., 1965 .

Rioch, Margaret J. et. al. "NIMH Study in Training Mental Health Counselors." American Journal of Orthopsychiatry. $1963,33,678-689$. 
Roth, Norman R. Reaching the Hard-To-Reach. A report of the Huntington-Gifford Project on Hard-To-Reach Youth. Syracuse, New York: The Huntington Family Centers, Inc., 1961.

Shapiro, Joan. "Dominant Leaders Among Slum Hotel Residents." American Journal of Orthopsychiatry. $1969,39(4)$.

Taber, Richard H. "A Systems Approach to the Delivery of Mental Health Services in Black Ghettos." American Journal of Orthopsychiatry. 1970,40 (4).

Taran, Freeda F. "The Utilization of Nonprofessional Personnel in Social Work Services." In Proceeding of Conference on new careers for disadvantaged youth. Washington, D. C.: Howard University, 1964.

Torrey, E. Fuller, "The Case for the Indigenous Therapist." Archives of General Psychiatry, 1969, 20, 365-373.

Wale, F. G. "The Division of Community Education--an Overview." The Journal of Social Issues. 1953, 9, $11-22$.

Weéd, V. and Denham, W. H. "Toward More Effective Use of the Nonprofessional Worker: a Recent Experiment." Social Work. $1961,6,29-36$.

Whyte, William F. Street Corner Society. The University of Chicago Press: Chicago. 1958.

Willner, M. "Unsupervised Family Day Care in New York City." Child Welfare, 1969,48 (6), 342-347. 